\title{
GESTÃO DE PRODUÇÃO DE CONTEÚDOS PARA EAD: ESTRATÉGIAS PARA ESTIMULAR A CRIATIVIDADE E PRODUÇÃO COLABORATIVA
}

\author{
RECIFE/PE JUNHO/2018
}

\author{
Andréa César Pedrosa da Silva - SER - andrea.cesar@sereducacional.com \\ Manuela Martins Alves Gomes - SER - manuela.martins@sereducacional.com
}

Tipo: Relato de Experiência Inovadora (EI)

Categoria: Gerenciamento e Logística

Setor Educacional: EDUCAÇÃO MÉDIA E TECNOLÓGICA, EDUCAÇÃO SUPERIOR, EDUCAÇÃO CORPORATIVA, EDUCAÇÃO CONTINUADA EM GERAL

\begin{abstract}
RESUMO
O crescimento da oferta de cursos na modalidade a distância aumentou na mesma proporção que a demanda para produção de recursos didáticos pensados e construídos para atender as especificidades de um processo de ensino e aprendizagem mediado por tecnologia. O impacto não está apenas no formato dos materiais produzidos, mas, de forma mais intensa, afeta o modo de fazer, que se encontra ainda alienado do pensar andragógico, com foco apenas nas métricas e padrões pré-estabelecidos, com ritmo ditado pela necessidade de oferta. Diante deste cenário, apresentamos uma experiência em gestão de uma equipe de produção de conteúdo para Ensino a Distância, de uma grande Instituição de Ensino Superior, com sua intencionalidade em trazer a equipe para um estado de apropriação e pertencimento da metodologia, com ênfase na necessidade constante de interação e formação continuada, promovendo a manutenção de um ambiente que estimule a criatividade e a produção colaborativa. Apresentaremos o FOCO EaD e suas estratégias para tornar o processo de produção de conteúdo para o Ensino a Distância ainda mais produtivo e prazeroso para cada membro da equipe
\end{abstract}

Palavras-chave: produção de material didático; ead; formação continuada ead; gestão ead

\section{AGRADECIMENTOS}

AO NOSSO GESTOR QUE APOSTOU NO FOCO EAD E A TODA EQUIPE QUE, CORAJOSAMENTE, SAIU DE SUA ZONA DE CONFORTO E, COM ENERGIA RENOVADA, PARTICIPA ATIVAMENTE DO PROJETO. 


\section{INTRODUÇÃO}

O professor Litto, em "Indicadores de uma Escola Moderna... Um "Checklist"' (2005), nos fala que "ambientes fragmentados e isolados tendem a permitir a geração de produtos fragmentados e isolados", tanto o aspecto da aprendizagem quanto de trabalho. Essa fragmentação é uma característica básica do processo de produção industrial, que imbuído do desejo de otimizar o tempo, aumentar a produção e melhorar a qualidade, acabou por tirar do trabalhador artífice o domínio do processo como um todo.

Otto Peters, fundador e $1^{\circ}$ Reitor da Universidade a Distância da Alemanha, lançou em 1967 uma monografia contendo os princípios da Teoria da Industrialização, analisando os pontos convergentes da produção industrial com a EaD. Basicamente a correlação encontrava-se na necessidade da racionalização, baseada na divisão do trabalho, possibilitando a oferta massiva de conteúdos educacionais sem a limitação do tempo e do espaço. A responsabilidade pela educação foi deslocada para a iniciativa privada, que tinha na oferta de um produto produzido de forma industrial, a garantia do lucro a partir do alcance em larga escala.

A EaD surgiu e ocupou um espaço gigantesco em detrimento das limitações reais da modalidade presencial, que além de não atender a demanda crescente de uma educação formal, não consegue chegar a lugares remotos.

O crescimento e a respectiva necessidade de racionalizar os processos para atender a demanda acabou gerando o mesmo problema dos processos de industrialização, porém com uma intensidade e comprometimento ainda maiores, pois não se tratava apenas de reproduzir movimentos precisos e calculados, mas, no contexto educacional, de se reproduzir o 'pensar' e os respectivos 'saberes' de forma mecanizada, sem reflexão crítica e ajustes necessários para tornar o processo de ensino e aprendizagem realmente eficaz.

O nosso 'produto' (perdoem o neologismo) não é tangível, e a consequência de produzilo como se assim o fosse acarretará consequências que já estamos começando a perceber, na evasão e na imagem manchada pela falta de qualidade de programas de formação rasos e recursos educacionais medíocres e descontextualizados.

O grande desafio é alcançar a 'sustentabilidade' de nossos processos, utilizando-a de maneira adequada e cuidando de nossa principal matéria prima: a produção intelectual, que não são máquinas e que precisam, de forma efetiva e perene, de condições que 
possibilitem o pensar criativo e inovador.

\section{PROBLEMA}

Em meio ao desenvolvimento das Tecnologias de Informação e Comunicação (TICs) e mídias sociais, a Educação a Distância ganha espaço como uma forma de possibilitar a conquista de uma formação superior sem a necessidade de aderir ao formato de estudo presencial tradicional.

Nesse contexto, entra em voga a produção de materiais didáticos através de um formato definido de estudo e atividades que sirvam como base para a construção do conhecimento dos discentes dos cursos EAD.

Segundo Zanetti (2015):

Os materiais didáticos devem ainda ser criados em consonância com os princípios pedagógicos do curso e, consequentemente, de acordo com o referencial teórico que o sustenta. A análise de um guia de estudo e de um vídeo pode nos revelar não apenas o conteúdo do qual ele é suporte, mas a forma como é entendido o processo de construção do conhecimento na proposta pedagógica daquele curso, ou seja, as concepções que o embasam. (Zanetti, 2015, p 97).

Sendo assim, entende-se que cada IES possui uma produção característica que esta em acordo com o projeto pedagógico criado para o curso ofertado. $E$ em consequência disso, independente da área de atuação (saúde, exatas ou humanas), deve existir um modelo de produção padrão que se adequa às especificidades de cada disciplina desenvolvida. Nesta grande IES a produção de conteúdos e todo o processo de construção das disciplinas estão associados a esta premissa.

A equipe de produção é dividida em quatro frentes: a capacitação dos professoresautores; o tratamento instrucional das produções; a revisão ortográfica; e a diagramação/ ilustração dos conteúdos para disponibilização no Ambiente Virtual de Aprendizagem (AVA).

Cada disciplina desenvolvida consta com um gama de recursos-padrão que formam o material de estudo dos discentes. E é em parceria com os professores autores que a equipe desenvolve os seguintes materiais conforme figura 1 
Guia de Estudo

(4 pordisciplina)
- Material queservecomo nortepara osalunos, originalmente escritopelo professore revisado pelos designers instrucionais. Em geral, consta de um arquivo interativo (com links, imagens etc.) entre 10 e 20 páginas diagramadas em formato de livreto digital. Săo 4 (quatro) guias pordisciplina, sendo um paracadaunidade detrabalhoconforme descrição donosso plano de ensino.
Questionários

(40 questōes por disciplina)
- Banco de questóes de múltipla escolha (40 questŏes, sendo 10 por unidade) que abarcam os assuntos trabalhados nos Guias, Livro-texto das disciplinas.
Desafio Colaborativo

(1 por disciplina)
- Atividade diferenciada que prevê a interação por parte dos alunos como forma de incentivar a discussão reflexiva entre eles.

Figura 1 - Descrição dos materiais desenvolvidos.

Para desenvolver estes materiais, foi estabelecido o seguinte fluxo de trabalho de acordo com figura 2.

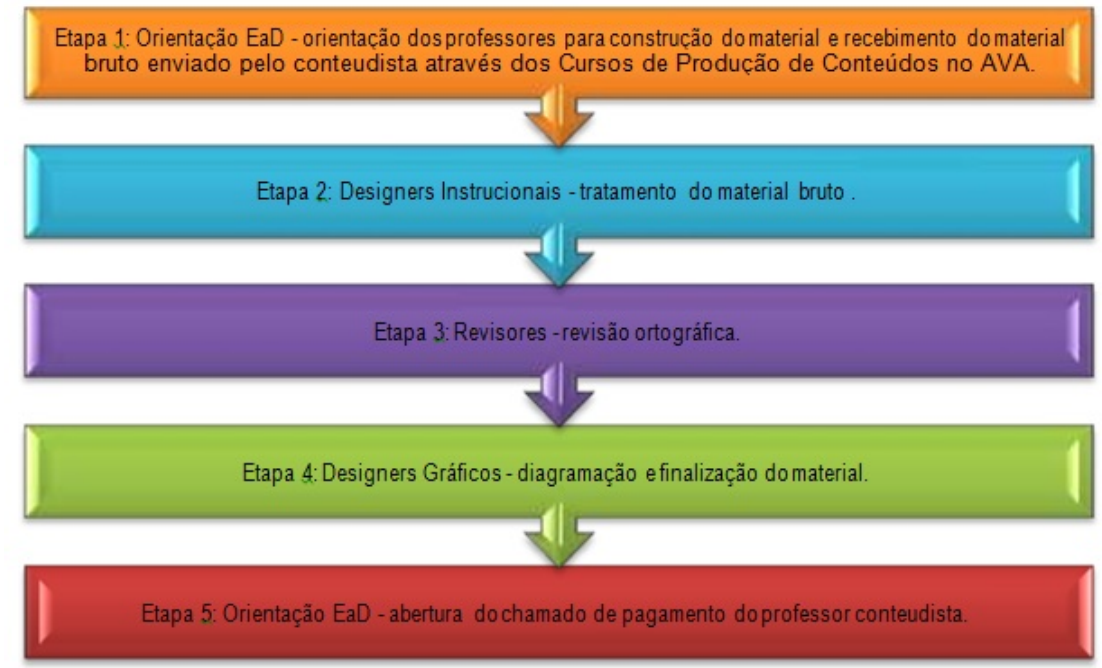

Figura 2 - Descrição fluxo de produção.

Além da produção escrita de materiais propriamente dita, conforme já explicamos acima, o processo de conteúdo também envolve a disponibilização de todos estes recursos no LMS utilizado, uma vez que outra parte da equipe trabalha na montagem e ajuste conforme necessidade em cada disciplina conforme figura 3. E por fim, temos ainda, uma equipe destinada ao acompanhamento de webconferencias gravadas por professores para auxiliar e acompanhar os discentes durante o semestre de acordo com 
a figura 4 abaixo.

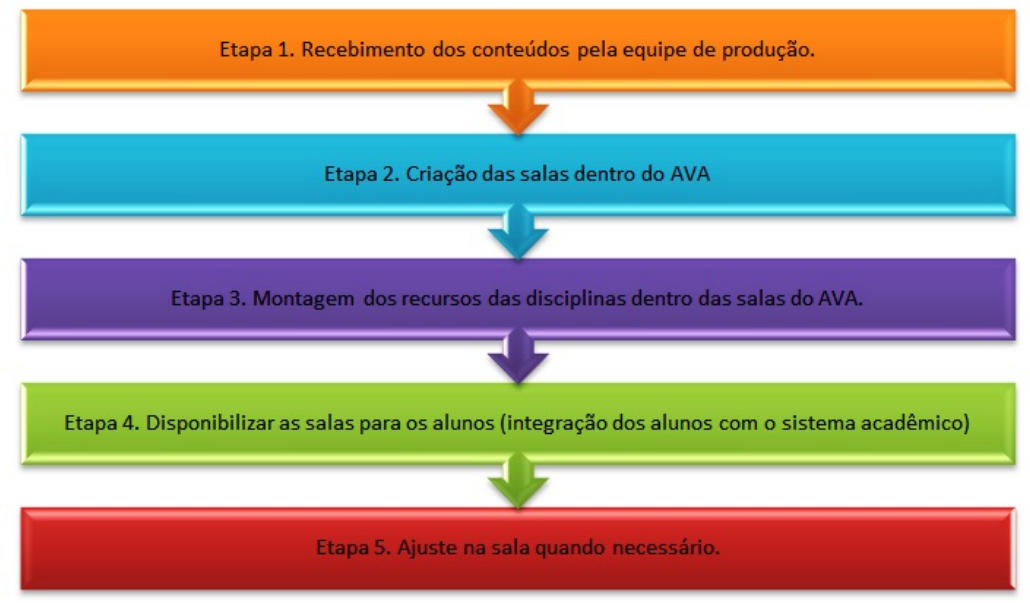

Figura 3 - Descrição fluxo de LMS

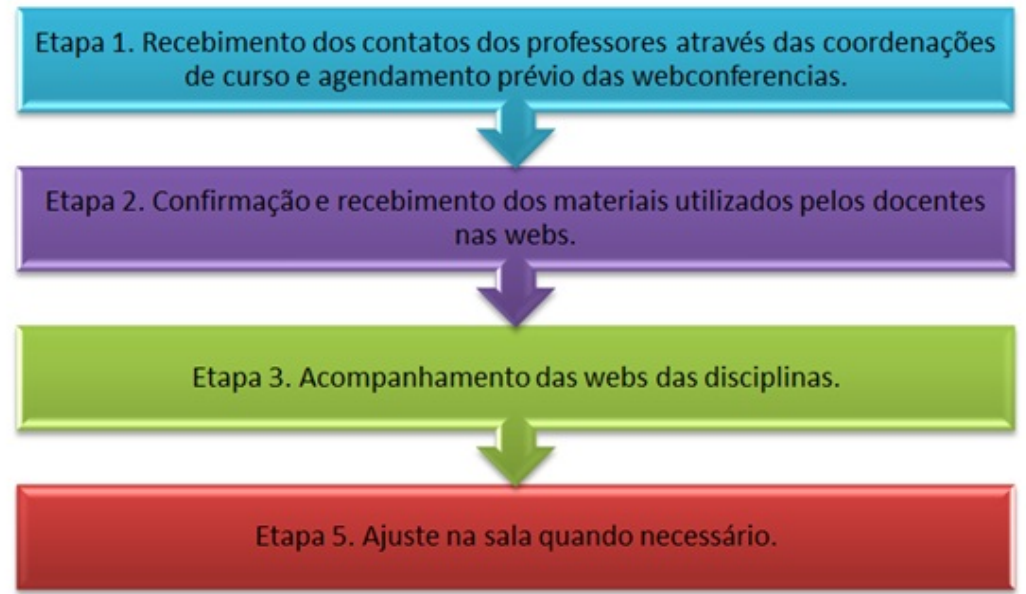

Figura 4 - Descrição fluxo de webconferências

Tendo em vista estes fluxos de atividades, segundo pesquisa interna realizada pela instituição voltada para a expansão do setor realizada em 2017, a equipe formada de produção desenvolve cerca de 200 disciplinas por ano para os cursos de graduação ofertados $100 \%$ a distância. E as equipes de LMS e webconferencia disponibilizam e acompanham o triplo de disciplinas no AVA para os alunos.

Afora este trabalho, existem mais iniciativas que também culminam na produção de materiais, montagem, disponibilização e acompanhamento dentro destes moldes, e que são realizadas pelas mesmas equipes, como: disciplinas para cursos técnicos, disciplinas utilizadas dentro do percentual de $20 \%$ nos cursos presenciais e disciplinas para cursos de pos-graduações a distância da IES. 
Foi, justamente, através desta pesquisa interna que notou-se a necessidade de investimento em formação e desenvolvimento intelectual para agregar conhecimentos e trazer inovações para estas equipes, problemática da qual gira em torno este relato. Então, a ideia da formação continuada começou a ser pensada em acordo com os pensamentos de Fusari (1998) e Nóvoa (1992) que:

[...] apontam para a necessidade de se avançar e criar um novo paradigma, no qual a formação do educador se efetive num continuum, processo em que a formação inicial, a formação contínua, a prática profissional, os saberes da profissão e a carreira profissional sejam elementos articulados entre si (FUSARI, 1998, p.538-9; NÓVOA, 1992).

. Altet (2001) completa ao destacar que:

A formação não pode mais consistir em uma modelização das tomadas de decisão, mas deve propor dispositivos variados e complementares que desenvolvam o saber-analisar, o saber-refletir, o saber-justificar, através de um trabalho do professor sobre suas próprias práticas e experiências (ALTET, 2001, p.34).

Assim, pensou-se que além da formação em si, proporcionada através de um momento de confluência de informações, de processos, dever-se-ia investir em uma diversidade de opiniões, pesquisas e tendências que culminassem em melhoria dos processos internos de produção e desempenho das funções dentro da equipe de desenvolvimento de conteúdo de forma mais produtiva.

\section{JUSTIFICATIVA}

O projeto que embasou o presente relato justifica-se na necessidade de investir no capital humano a fim de promover encontros sistemáticos que diminuam a alienação do pensar andragógico e que colaborem para a dissociação do desenvolvimento de disciplinas com base, apenas, em princípios e padrões que se transfiguram em uma linha de produção fordista.

É preciso aprofundar-se em pesquisas, brainstormigs, debates e discursões que tragam à tona estratégias criativas de forma colaborativa para construção e implantação de novos paradigmas na produção de materiais.

\section{OBJETIVOS}

\section{Objetivo Geral}

O Programa FOCO EaD (Formação Continuada em EaD), tem por objetivo integrar a equipe de produção de recursos didáticos de nossa IES, de forma que todos conheçam todas as etapas do processo de produção e possam interagir de maneira colaborativa e contextualizada com as inovações tecnológicas e metodológicas que afetam diretamente 
a modalidade de ensino a distância.

\section{Objetivos Especifficos}

-Estimular o bom clima organizacional;

- Incentivar a partilha de informações acerca de temas relacionados com a EaD;

- Demandar pesquisas e desenvolvimentos de objetos de aprendizagem;

- Provocar o olhar crítico sobre o processo e os materiais produzidos;

- Otimizar o tempo de produção, reduzindo o retrabalho;

- Promover a melhoria contínua da qualidade dos recursos produzidos.

\section{FUNDAMENTAÇÃO TEÓRICA}

Diante deste cenário, a gestão colaborativa se faz presente como pilar de sustentação desta experiência. É através dela que pensamos a formatação de um projeto que viesse a envolver todos os membros da equipe em busca de novos horizontes, pois como ressalta Fullan \& Hargreaves (2000, p. 66) "o trabalho em conjunto implica e cria uma interdependência mais forte, uma responsabilidade compartilhada e um aperfeiçoamento coletivos...".

Dessa forma, pensar em formação continuada e implantar um projeto voltado para isso se baseia também em um "sistema flexível, permeável e aberto a revisões e depurações de acordo com as necessidades" de produção das disciplinas levando em consideração as "condições de trabalho da equipe, evidenciando uma práxis transformadora que extrapola as ações dessa equipe e se revela nas atividades propostas aos alunos" (FERREIRA et al, 2006, p. 03).

E, ainda, não podemos esquecer-nos do ultimo pilar desta iniciativa que é a criatividade na produção colaborativa. Para Santeiro, Santeiro e Andrade (2004) a criatividade tem sido reconhecida como importante para o desenvolvimento e compreensão do ser humano e de suas manifestações, uma vez que considera, desde características intrínsecas da pessoa criativa (habilidades cognitivas) até o ambiente onde esta se insere (família, escola e trabalho), atuando estas instâncias reciprocamente umas sobre as outras. Em nosso contexto, a relevância da criatividade esta no encontro de ideias que podem propiciar a inovação.

\section{METODOLOGIA}

Bates (2016), nos fala acerca do "vinho velho na garrafa nova", pontuando a tendência de adaptar para um formato tecnológico os métodos de ensino de sala de aula 
presencial:

O vinho velho pode ser um vinho bom, a garrafa sendo velha ou nova. O que importa é se o design da aula atende às necessidades de mudança de uma era digital. Todavia, adicionar tecnologia à dinâmica ou replicar o mesmo design no mundo virtual não significa atender às demandas de mudança. (BATES, 2016, p.167)

A necessidade de quebrar velhos paradigmas educacionais está presente em todas as etapas de produção de conteúdos para EaD. Engana-se quem pensa que só o professor precisa aceitar as mudanças. Muitas vezes grandes possiblidades de inovação são abortadas na esteira de produção, por agentes da equipe, que também têm uma visão cristalizada no modelo presencial.

Todos precisam repensar suas concepções sobre o que vem a ser um processo educacional realmente eficiente e eficaz. Quando o professor apresentar uma ideia 'mirabolante', o design instrucional/educacional deve estar com a mente aberta para pensar na melhor forma de implementar, ou de aproveitar parcialmente, caso não seja plenamente factível. Uma inovação na modelagem da sala no AVA deve ser encarada positivamente pela equipe do LMS, analisando de forma objetiva os prós e os contras. Sugestões de inovação na forma como produzimos as webconferências devem ser tratadas com muito carinho e empatia pelos assistentes de WEB.

Os processos estão intimamente relacionados, e todos, sem exceção, devem compreender a dinâmica e a linguagem mais eficaz para o ensino a distância. $O$ aproveitamento do 'bom vinho' é viabilizado com o concurso de uma modelagem educacional afinada com as peculiaridades da EaD.

O FOCO EaD lança mão de duas ferramentas que nos ajudam na sistematização das ações e discussões:

1- Design Thinking: uma abordagem que nos permite modelar previamente as ideias que darão vida aos projetos de inovação ou melhoria de nossos processos. É a etapa onde a criatividade é estimulada ao máximo, nas seguintes etapas:

- Conhecer o cenário

- Pesquisar

- Gerar ideias

- Prototipar

- Testar

2 - O modelo ADDIE, que apesar das reservas quanto ao contexto de sua concepção, atende às nossas necessidades de 'amarrar' um fluxo com uma linha condutora 
padronizada, baseada nas seguintes etapas:

- Análise: acontecem rodadas de discussões coletivas, onde todos os aspectos do projeto são analisados de forma interdisciplinar e cada ator tecerá suas considerações, de acordo com sua expertise e atuação no processo;

- Desenho: nesta etapa acontece a modelagem do projeto, que pode seguir um padrão pré-existente ou não;

- Desenvolvimento: cada frente de trabalho assumirá sua parte no processo de desenvolvimento do projeto, partilhando com os colegas a evolução;

- Implementação: o projeto é implementado, com registro dos papeis de cada agente.

- Avaliação: consiste na prática de avaliar periodicamente o andamento dos projetos implementados.

A periodicidade do FOCO é bimestral, e todos os registros ficam disponíveis para toda equipe no repositório compartilhado na nuvem educacional, para acesso e consultas, sempre que necessário.

\section{CONSIDERAÇÕES FINAIS E CONCLUSÃO}

Entendemos que não é possível produzir uma educação de qualidade, seja ela presencial ou a distância, sem a participação crítica e construtiva de todos os atores envolvidos no processo.

Provocar uma reflexão sobre o nosso papel dentro do contexto da oferta de ensino a distância foi o primeiro passo. Neste momento, cada um refletiu sobre o próprio ofício e o impacto que o mesmo tem dentro do processo global.

Olhar o 'fazer' do colega e enxergar o impacto e a relação que a tarefa dele tem com a nossa (ou vice versa), foi o segundo momento. Se apropriar de todo processo produtivo e do papel social que o nosso trabalho tem, foi a culminância.

O andamento consistirá em não deixar essa chama apagar, e de forma sistemática, porém, empaticamente humanizada, assegurar que o nosso ofício atenda a nossa necessidade de realização e que seja muito prazeroso ver o fruto de nosso trabalho contribuir para a construção de um mundo melhor, que, como dizia o mestre Paulo Freire, só é possível com Educação, e pedindo licença, acrescentamos que apenas a Educação a Distância pode chegar a todos os lugares, socializando oportunidades de uma vida melhor para todos.

\section{REFERÊNCIAS}


ALTET, M. et. al. Formando professores profissionais: quais estratégias? Quais competências? 2.ed. Porto Alegre: Artmed Editora, 2001.

BATES, A. W. (Tony). Educar na Era Digital - Design, Ensino e Aprendizagem. São Paulo. Artesanato Educacional. 2016.

PETERS, O. (1967) Distance education and industrial production: a comparative interpretation in outline. Disponível em http://www.c3l.unioldenburg.de/cde/found/peters67.htm Acesso em 19/05/2018.

FERREIRA, Felipe Casaburi; et al. A complexidade e a complementaridade de saberes e competências profissionais na implementação de um projeto de formação de gestores escolares via Internet. 2006.2 Disponível em: http://cetrans.com.br/assets/artigoscongresso/Maria_Elizabeth_Bianconcini_de_Almeida et_al.pdf. Acesso em: 20/05/2018.

FULLAN, Michael \& HARGREAVES, Andy. A Escola como Organização Aprendente. Porto Alegre: Artes Médias Sul, 2000.

FUSARI, J. C. Formação contínua de professores: o papel do Estado, da universidade e do sindicato. In: ENCONTRO NACIONAL DE DIDÁTICA E PRÁTICA DE ENSINO, 9., 1998, Águas de Lindóia. Conferências, mesas-redondas e simpósios. Petrópolis: Vozes, 1998.

LITTO, F M. (2005). Indicadores de uma Escola Moderna... Um "Checklist". Disponível em

http://www.abed.org.br/site/pt/midiateca/textos_ead/669/2005/11/indicadores_de_uma_e scola_moderna....um_checklist_Acesso em 14/05/2018

LÉVY, Pierre. Cibercultura. São Paulo: Editora 34, 2009.

NÓVOA, A. Formação de professores e profissão docente. In: Os professores e a sua formação. Lisboa: Dom Quixote, 1992. p.13- 33.

NÓVOA, A.; FINGER, M. O método (auto) biográfico e a formação. Lisboa: Ministério da Saúde, 1988.

SANTEIRO, T.V., Santeiro, F.R.M., Andrade, I.R. Professor facilitador e inibidor da criatividade segundo universitários. Maringá: Revista Psicologia em Estudo, 2004.

SIEMENS, G. (2004). CONECTIVISMO. Uma Teoria de Aprendizagem para a Idade Digital. Disponível em http://usuarios.upf.br/ teixeira/livros/conectivismo\%5Bsiemens\%5D.pdf acesso:24/04/2017.

ZANETTI, Alexsandra. Elaboração de Materiais Didáticos para Educação a Distância. Disponivel em http://www.cead.ufj..br/wpcontent/uploads/2015/05/media_biblioteca_elaboracao_materiais.pdf. Acesso: 20/05/2018. 